\title{
The Eufaula Mound: Contributions to the Spiro Focus
}

Kenneth G. Orr

Unknown

Follow this and additional works at: https://scholarworks.sfasu.edu/ita

Part of the American Material Culture Commons, Archaeological Anthropology Commons, Environmental Studies Commons, Other American Studies Commons, Other Arts and Humanities Commons, Other History of Art, Architecture, and Archaeology Commons, and the United States History Commons

Tell us how this article helped you.

This Article is brought to you for free and open access by the Center for Regional Heritage Research at SFA ScholarWorks. It has been accepted for inclusion in Index of Texas Archaeology: Open Access Gray Literature from the Lone Star State by an authorized editor of SFA ScholarWorks. For more information, please contact cdsscholarworks@sfasu.edu. 


\section{The Eufaula Mound: Contributions to the Spiro Focus \\ Creative Commons License \\ (c) (1) \& 8}

This work is licensed under a Creative Commons Attribution-NonCommercial 4.0 International License 


\title{
THE EUFAULA MOUND: CONTRIBUTIONS TO THE SPIRO FOCUS
}

\author{
Kenneth G. Orr
}

\section{INTRODUCTION: PURPOSE AND SOURCES}

The main aim of the paper is the comparison of two archaeological sites, (i) the Eufaula site of McIntosh County [ed. note: 34MI45], and (2) the Spiro site of Leflore County, Okla. Purpose of the comparison is to indicate the relationship between the 2 sites, thereby establishing a Spiro Focus, the ramifications and general affiliations of which will be suggested.

The thesis is based on original research coming out of my experience as Project Superintendent of various units of the Oklahoma WPA Project. The Project, sponsored by the university of Oklahoma and directed by Dr. F.E. Clements, has carried on large scale excavations in Oklahoma since 1936. At that time the Spiro Mound group, in the east central part of the state, was opened up. In the two years from 1936 to 1938 a crew of 70 WPA laborers, under the direction of trained archaeologists, unearthed quantities of archeological material. The main bulk of material from the "Great Temple" Mound was excavated under the direction of Mr. Joe Finkelstein. ${ }^{1}$ It was my privi- lege to analyze the material excavated by him. I also excavated the Spiro Village and a series of villages in the vicinity of the Mound group. ${ }^{2}$ Both groups of data will be utilized.

During the summer of 1940 I supervised the excavation of the Eufaula Mound, a site 50 miles west of the Spiro Mounds. This excavation was also under the direction of Dr. Clements. It was sponsored by the Creek Indian Memorial Association, whose museum in Okmulgee, Okla. now displays most of the material. The striking similarity between the Spiro and Eufaula material led to a comparison, the results of which are indicated in this thesis.

Although the Eufaula Component is completely reported here, the Spiro Component is merely outlined and compared. Dr. Clements is, at the present time, preparing a work on the Spiro Mounds which will be completely definitive. Consequently, this thesis must be regarded as a contribution to the Spiro Focus, rather than as a final report on that Focus. 


\section{METHOD OF APPROACH}

The method of approach is that known as the Midwestern Taxonomic method ${ }^{3}$, a system for classifying archaeological material on the basis of associated traits. The units of the system are five in number: (1) focus, "made up of a group of communities with a preponderating majority of determinants in common"; (2) aspect, "communities with an approximate majority of traits in common"; (3) phase, "communities with a small but significant number of traits in common"; (4) pattern, "communities with fundamental determinants in common"4. The fifth unit is "base", consisting of 2 patterns with "certain general linked traits shared by both" . The term "Community" is defined as "the complete cultural manifestation of a local group or as much of it as is determined by archaeological exploration". ${ }^{6}$ Our components consist of Eufaula and Spiro burial components. Although the burden of proof for the establishment of the focus will rest on a comparison of burial materials, data from the villages of the two sites will be used to supplement and support the argument.

The secondary purpose of the paper, that of suggesting the affiliations of the Spiro
Focus, will be approached by the method suggested by Cole and Deuel, that of building up an aspect unit from a series of related foci units. ${ }^{7}$ The determinants of the Spiro Focus will be compared with the traits of a series of components for the purpose of suggesting an aspect unit inclusive of all. Our data, since it will deal in detail with but one focus, will allow us only to postulate such an aspect. Nevertheless, we may conjecture the ramifications and affiliations of the postulated aspect. However, quite within the bounds of our data is the tentative assignment of the Spiro Focus to a phase and a pattern. The problems of cultural and chronological relationships raised by the comparison of the Spiro Focus with related sites will be briefly dealt with and broadly interpreted.

Briefly, we hope by a detailed study of a single component and its related components to suggest in broad outline (1) cultural developments in the archaeological area now known as "Caddoan" and (2) the relation of such developments to the problems of Mississippi Valley archaeology.

\section{THE EUFAULA MOUND}

The Eufaula Site, a mound surrounded by a village, was located on the north bank of the Canadian River near the town of Eufaula in east-central Oklahoma. At the time of the excavation in the summer of 1940 only the stump of a mound (symbol- ized as Mi.Gr. 1 and known as the Eufaula Mound) and an area covered by village debris remained on the wind eroded site. The mound was a low shield-shaped structure measuring $174^{\prime}$ north-south, $110^{\prime}$ east-west, and $4.5^{\mathrm{t}}$ high. The wide, sandy 
bottomland of the Canadian River is at this point surrounded by the northern fringe of the Ouachita Mountains, wooded hills with an elevation of about $850^{\prime}$.

Although the mound had undergone random digging in previous excavations, such excavations served the purpose of creating interest in the mound. The Creek Indian Memorial Association of Okmulgee, Okla. secured a lease on the site, and sponsored a unit of the WPA Archaeological Project to excavate the mound. Under the direction of Dr. Forrest E. Clements and supervision of the writer, the mound was completely excavated by the use of controlled methods. A coordinated grid system was placed over the mound. All artifacts and features within the mound were located horizontally in reference to the grid system. Vertical placement was determined by "shooting" with a transit from Station \#1 at an elevation of 550'. The records included: profile maps, a site map, maps of all features, data forms, artifact sketches and daily notes, as well as photographs. A crew of 14 WPA laborers carefully excavated about $60,000 \mathrm{ft}$. of artifact-bearing earth in 40 working days.

A study of the profiles, made at each $5^{\prime}$ strip or row, indicated the mound consisted of a main, sand stratum flanked on all sides by a thick stratum of wash which had eroded from the mound (Fig. 1). Originally, the mound must have been at twice as high $\left(10^{\prime}\right)$. Burials with artifacts were found at all levels of the mound. Since the mound lacked artificial stratification, and since the lowest burial was similar in type and contents with the highest, time differences were not present. Of particular inter- est was the occurrence of five thin, brown soil lines which, running through the burials, extended in a "erratic" manner through the main stratum. It is thought the lines resulted from a filtering out of silt particles following heavy rains. A stratum of clay that underlay the mound had continuously trapped rain water, making the sand "quick". The lines suggested that the mound had been built in stages within a short period of time, since old vegetation lines were absent.

The skeletal material in the burials was in a bad state of preservation. However, certain facts were obtained from a study of the fragments. One hundred and thirtynine individuals were unearthed in 101 features. Two main burial types were noted: (1) single burials, and (2) group burials containing from two to seven individuals. The most common type of orientation was the semi-flexed position. Fully flexed burials occurred. Heads were oriented in all directions (Fig. 1-C). Within recent time another type of burial, the coffin burial, was added to the mound (Fig. 1-B).

The aboriginal physical type was barely hinted at by badly decayed, skeletal fragments. The Eufaula Mound people ranged in height from $5^{\prime}$ (presumably female) to $5^{\prime}, 9^{\prime \prime}$ (presumably male). Antemortem deformation of the cranium was not found. Teeth appeared for the most part free from caries. Associated with the burials were a series of artifacts, the placement of which (excepting earspools, beads, and mask) had no denotable significance.

The Eufaula Mound people were 


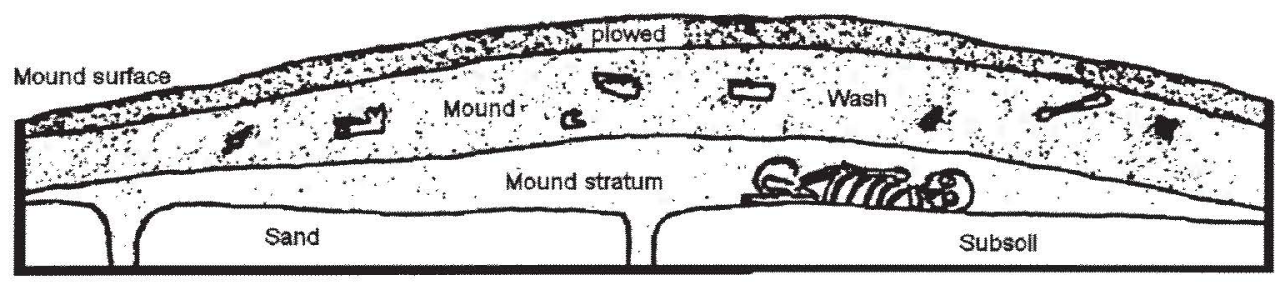

Base of excavation

A. Row 1 - at edge of mound

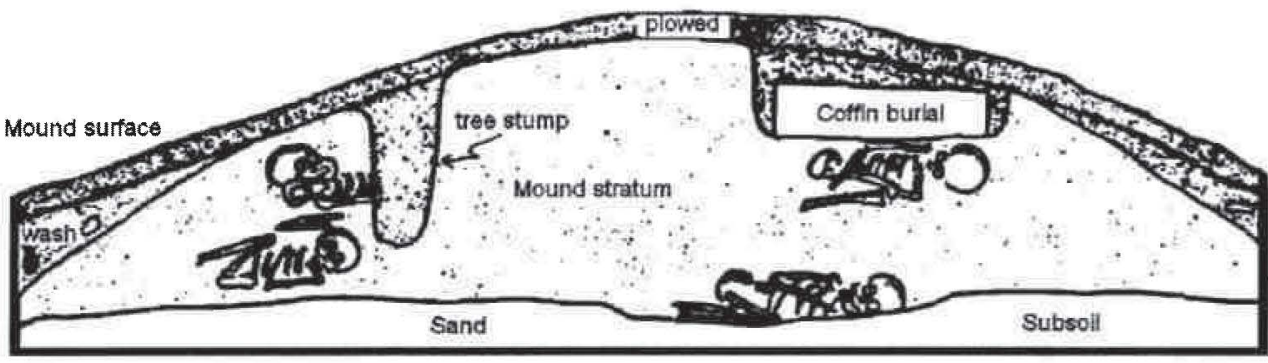

Base of excavation

B. Row $7-35$ feet in the mound

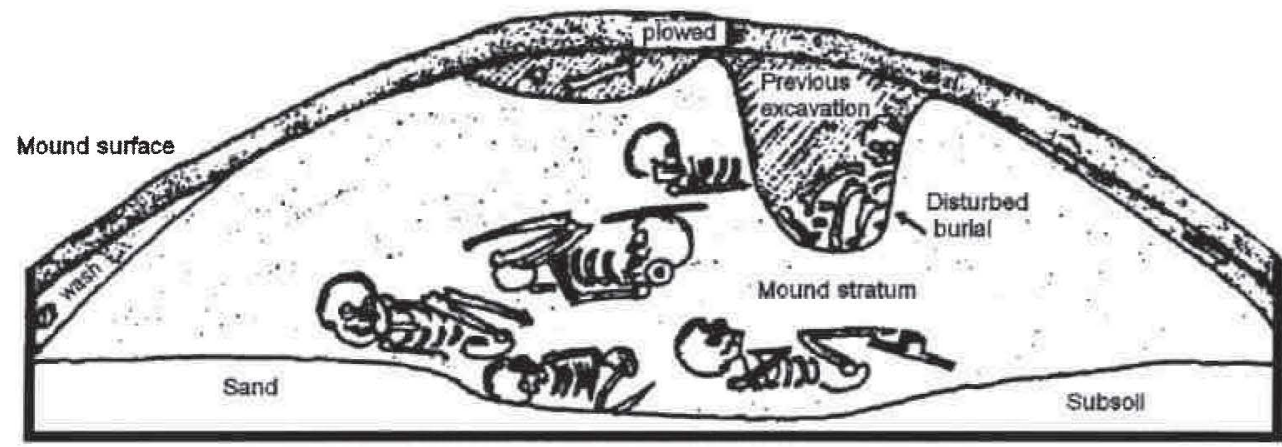

C. Row 12 - the middle of the mound



Base of excavation

D. Row 27 - near the end of the mound

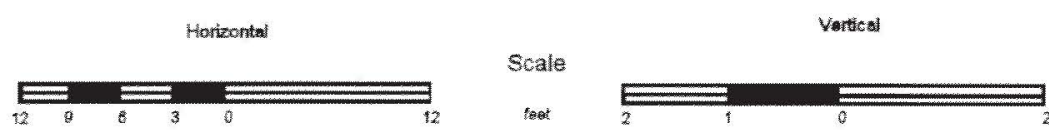

Figure 1. Selected profiles from the Eufaula Mound. 


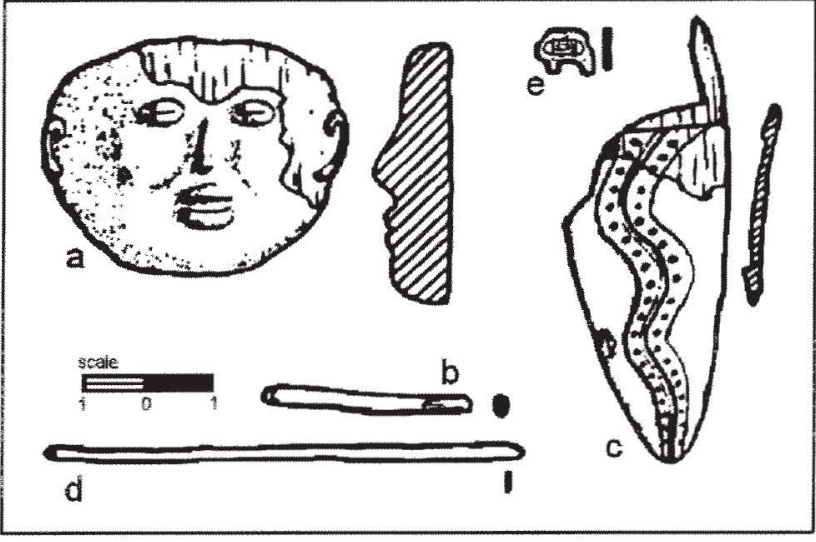

Figure 2. Sundry artifacts from the Eufaula component. a) copper covered mask; b) cylinder tip; c. coppercovered "blade"; $d$. copper bodkin (no scale); $e$ ) Caucasian object (instrusive?).

thick (over $0.8 \mathrm{~cm}$ ), dun or dun-orange ware tempered with both sherds and bone fragments. The former was represented by six restorable vessels and the latter by sherd fragments (Fig. 3). Vessel forms included a wide, cylindrical bowl with a convex base, a hemispherical bowl, a small pot, and bottles with conic necks and tripod bases. Particularly striking were the carefully incised designs found on the vessels. The main design was an "S" scroll which interlocks a number of times in a band (Fig. 3, a,b). Reed punctates were used as an area-filling device.

excellent craftsmen in clay, stone, bone, wood, and copper. Although both clay and stone, being indestructible, were plentiful, only a few bone and wood fragments were found, preserved by association with copper salts. Pottery was made by the coiling technique. The surface of the ware was smoothed with a pebble. Stone was both ground and chipped. Hard, gray limestone and a black, metamorphic stone were first pecked into shape by the use of a hammerstone, then ground and polished. Flint was chipped into small, delicate forms, presumably by pressure flaking. Bone was cut and polished. A few fragments of wood suggested the presence of well developed carving techniques All the materials, excepting bone, were shaped in a variety of forms, both simple and complex, and bore symmetrical incised designs.

Two main types of pottery were found: (1) a thin, highly polished, brown and black ware with sherd tempering, and (2)

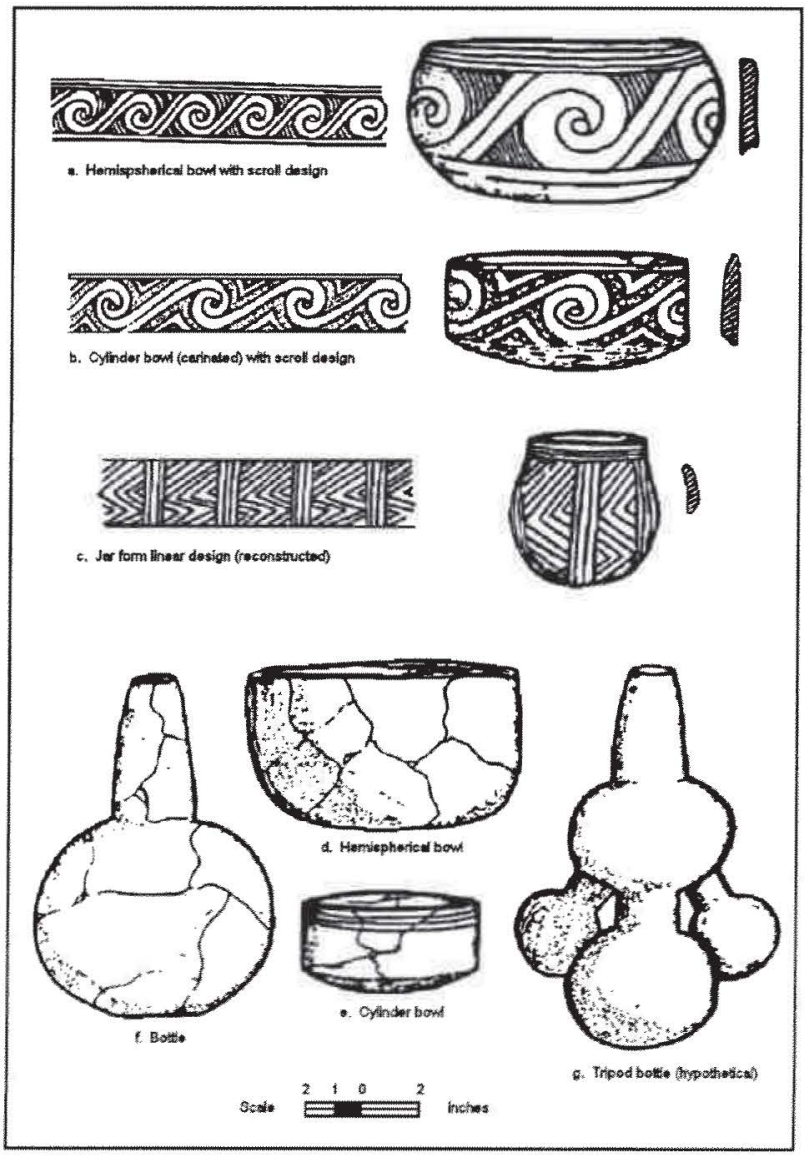

Figure 3. Pottery vessels from the Eufaula component. 


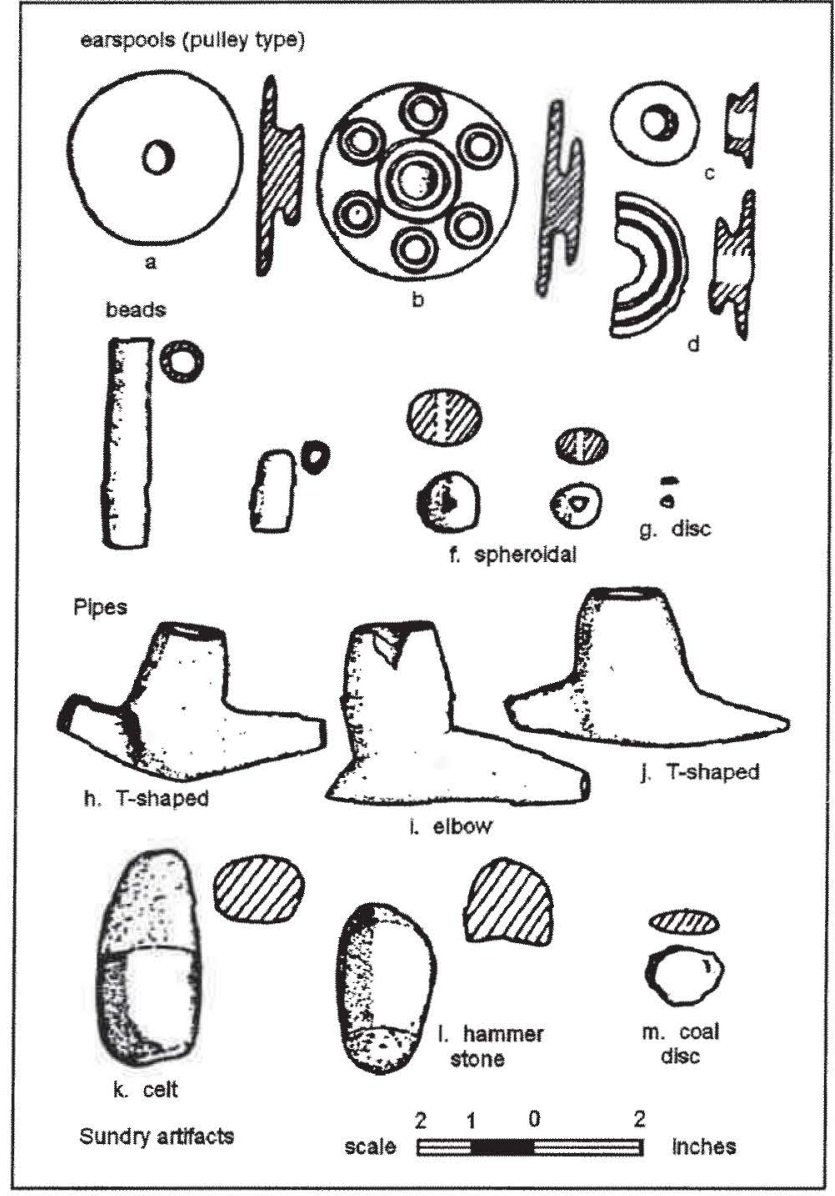

Figure 4. Ground stone artifacts: Eufaula component.

Ground stone artifacts included: earspools of the pulley type, the outer facet of which occasionally was incised with concentric circles and covered by a copper veneer; "T-shaped" and elbow pipes; manos; celts; a hammerstone; a hoe; and spheroidal beads (Fig. 4). Caches of river pebbles were thought to be the "rattlers" of decomposed rattles.

The majority of the chipped flint artifacts were small (average length $2.5 \mathrm{~cm}$ ), delicately formed points (Fig. 5). Pink, brown, black, and translucent flints were used. The series of forms found were based on the triangular, notched point and the barbed point with slightly expanding stem. A third well-defined type was the campanulated form. Many of the points had serrated edges, and horizontal notches in the basal section in addition to the body notches. Only five of the total 107 points were large ones (length over $6 \mathrm{~cm}$ ). The large points were of two forms: (1) shouldered point with contracting, tang stem, (2) barbed point with expanding stem. It was suggested that the large point was a more "utilitarian" point, not frequent in the burials where the unused, small, "ceremonial" points occurred in abundance.

Large blades ( 21 to $28 \mathrm{~cm}$ long) occurred in a cache. There were five of them, delicately chipped into fusielliptical and elliptical forms (Fig. 5, V). The wooden artifacts included: a small mask of the human face (Figure $2 a)$; a section of a "blade" with serpentine design (Figure 2c); a fragment of a thin cylinder (Fig. 2b). Attention was called to the unusual find of a previous excavation which consisted of two wooden artifacts, each about a foot in length, exactly simulating large, flint blades. ${ }^{9}$ The only other organic material found was bone, used for disc beads and "wrist guards". Since the grave soil in most cases was richly discolored, it was thought that the organic artifacts found represented only a small percentage of those originally present. The absence of shell by no means precludes the initial presence of this material in the burials.

A long "bodkin" of exceptionally pure copper was found (Fig. 2d). Copper was 
also used as veneer on wood and stone. This metal was evidently native copper which had been cold hammered into shape. Nodules of galena occurred singly and in groups of two to five in the burials. The carbonate covering on the galena balls had possibly been utilized as white paint. Other pigments were red ocre (sic), kaolin, and glauconite found in small lumps or as a coating on artifacts (celt with red pigment, blade with green pigment). Perhaps the most controversial object found in the mound was a piece of pewter-like metal of Caucasian origin, bearing the stamped numerals "1618" (Fig. 2e). Due to the liquid nature of the sand following heavy rains, this object may have filtered down into burial \#36 from the above intrusive burials (coffins). Although no clear evidence of intrusion was noted in the soil, the object should be regarded with some suspicion.

In brief:

1. The Eufaula Mound excavation uncovered mortuary part of a single, cultural component. One hundred and thirty-nine individuals were found along with considerable burial furniture.

2. As evidenced by the burial furniture, the Eufaula Site people were skilled in the manufacture of pottery, ground and chipped stone, wooden, bone and metal artifacts. Most outstanding of the artifacts were: wide cylinder vessels incised with symmetric, interlocking " $\mathrm{S}$ " scrolls; stone

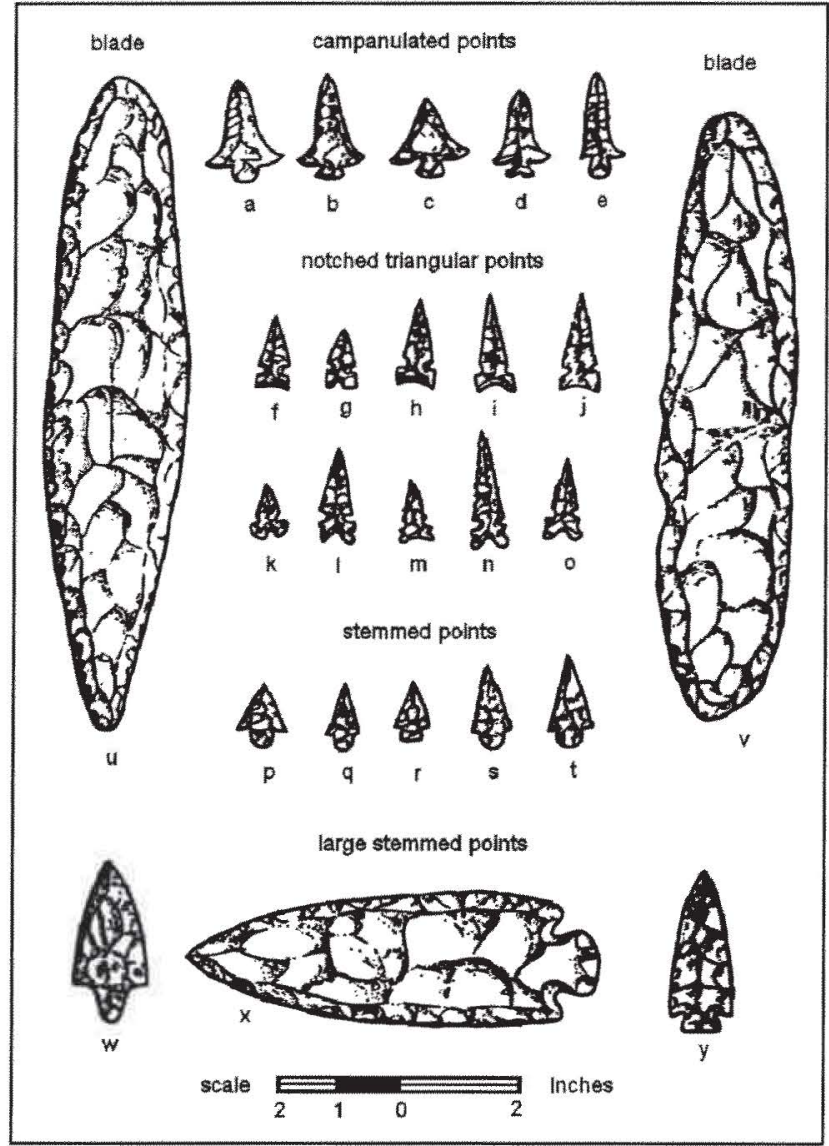

Figure 5. Chipped stone artifacts of the Eufaula component.

earspools and pipes; chipped points; and a copper-covered wooden mask and blade.

3. The chronological position of the site may be suggested by the metal fragment which bears the numerals "1618". If in situ, it suggests a proto-historic dating of the site; if not, the site is prehistoric. Evidence of Caucasian contact depends on the doubtful metal fragment. 


\section{A COMPARISON OF THE EUFAULA MOUND AND THE SPIRO MOUNDS Trait List Comparison}

The problem of this section is the comparison of two Indian burial mounds situated 50 miles apart. Before noting the details of features and artifacts within the mounds of the two sites, let us note broad similarities. Both are bottom land sites located on the same river system (Arkansas River and its tributary Canadian River). Both consist of burial mounds surrounded by a village ${ }^{10}$ Furthermore, they are in the same physiographic province (Ouachita). As we have indicated, the Eufaula site may be considered as a single cultural component. Although evidence of some cultural admixture was found in the Spiro Mound, the main body of the material was typologically and stratigraphically determined as belonging also to a single component. We are thus comparing two cultural complexes. Within each complex the artifacts and features are, as far as can be determined, genetically related. Our problem, then, is to determine the degree of relationship which existed between the Eufaula and Spiro components.

The method of comparing the two components is simply by aligning the trait lists $^{11}$ side by side (Table 1). The Eufaula traits will be presented first, then the presence, absence, abundance or rarity of each Eufaula trait will be noted in the Spiro list. In addition a fairly complete list of Spiro traits not found at Eufaula will be included.

Table 1. Trait List.

\begin{tabular}{|c|c|c|c|}
\hline \multicolumn{2}{|r|}{ Trait type } & Eufaula & Spiro \\
\hline \multirow[t]{5}{*}{ Burial: } & \multirow[t]{2}{*}{ type } & group & abundant \\
\hline & & single & present \\
\hline & \multirow[t]{2}{*}{ orientation } & semi-flexed & abundant $^{a}$ \\
\hline & & full-flexed & present \\
\hline & physical type & unknown & unknown \\
\hline \multirow[t]{7}{*}{ Ceramics: } & \multirow[t]{3}{*}{ temper } & sherd & abundant \\
\hline & & bone and sherd & abundant \\
\hline & & shell (rare) & $\operatorname{rare}^{b}$ \\
\hline & \multirow[t]{4}{*}{ ware } & thin, polished brown & abundant \\
\hline & & thin, polished black & abundant \\
\hline & & thick, dun (rare) & rare (abundant in village) \\
\hline & & red slip & Present ${ }^{\circ}$ \\
\hline
\end{tabular}




\begin{tabular}{|c|c|c|c|c|}
\hline \multicolumn{3}{|c|}{ Trait type } & Eufaula & Spiro \\
\hline & \multirow{5}{*}{\multicolumn{2}{|c|}{ form }} & cylinder bowl & abundant \\
\hline & & & hemispherical bowl & present \\
\hline & & & jar (type Fig. 2-c) & present \\
\hline & & & bottle, conic neck & abundant \\
\hline & & & bottle, tipod base & absent $^{d}$ \\
\hline & \multirow[t]{13}{*}{ designs: } & \multirow[t]{5}{*}{ techniques } & incised & present \\
\hline & & & engraved & abundant \\
\hline & & & punctate & present \\
\hline & & & applique & present \\
\hline & & & precise execution & abundant $^{\mathrm{e}}$ \\
\hline & & \multirow[t]{4}{*}{ motif } & "S" scroll & abundant \\
\hline & & & reed punctates & present \\
\hline & & & "Zig-zag" & present \\
\hline & & & three parallel lines & abundant ${ }^{\mathrm{f}}$ \\
\hline & & \multirow[t]{4}{*}{ arrangement } & bands around body & abundant \\
\hline & & & interlocking scrolls & abundant \\
\hline & & & rectangular panels & abundant \\
\hline & & & grooved lips & present $^{\mathrm{g}}$ \\
\hline & \multicolumn{2}{|l|}{ pipe } & & footnote $^{\mathrm{h}}$ \\
\hline \multirow[t]{13}{*}{ Ground stone: } & \multirow{3}{*}{\multicolumn{2}{|c|}{ pipe }} & T-shaped & abundant \\
\hline & & & elbow & present \\
\hline & & & effigy (?) & present $^{\mathrm{i}}$ \\
\hline & \multirow{3}{*}{\multicolumn{2}{|c|}{ earspools }} & pulley & abundant \\
\hline & & & with copper veneer & abundant \\
\hline & & & with concentric circles & present $^{\mathrm{j}}$ \\
\hline & \multicolumn{2}{|l|}{ mano } & rectangular, finger holds & present \\
\hline & \multicolumn{2}{|l|}{ celt } & elliptical celt & abundant ${ }^{k}$ \\
\hline & \multirow{5}{*}{\multicolumn{2}{|c|}{ additional }} & "whetstone" & present \\
\hline & & & quartzite, pecking stone & present \\
\hline & & & coal disc & present \\
\hline & & & "hoe" (village) & present \\
\hline & & & rattle pebbles & present $^{\text {th }}$ \\
\hline
\end{tabular}




\begin{tabular}{|c|c|c|c|c|}
\hline \multicolumn{3}{|c|}{ Trait type } & Eufaula & Spiro \\
\hline & \multirow{2}{*}{\multicolumn{2}{|c|}{ bead }} & of quartz crystal & absent \\
\hline & & & spheroidal of black stone & abundant \\
\hline \multirow[t]{12}{*}{ Chipped stone: } & \multirow[t]{10}{*}{ points: } & \multirow[t]{6}{*}{ small } & notched triangular & abundant \\
\hline & & & with serrated edges & present \\
\hline & & & with "pike" point & present \\
\hline & & & basal part notched & absent \\
\hline & & & stemmed with barbs & abundant $^{\mathrm{n}}$ \\
\hline & & & above with serrated edges & present \\
\hline & & \multirow[t]{2}{*}{ campanulated } & broad & absent \\
\hline & & & long, narrow & rare \\
\hline & & \multirow[t]{2}{*}{ large } & shouldered, long stem & rare \\
\hline & & & expanding stem & rare \\
\hline & \multirow{2}{*}{\multicolumn{2}{|c|}{ blades }} & long, fusi-elliptical & abundant \\
\hline & & & elliptical, rounded ends & abundant \\
\hline \multirow{3}{*}{\multicolumn{3}{|c|}{ Wood }} & human face mask & present \\
\hline & & & "flint" blades & absent \\
\hline & & & section of thin cylinder & present $^{\circ}$ \\
\hline \multirow{2}{*}{\multicolumn{3}{|c|}{ Bone }} & disc beads & present \\
\hline & & & "wrist guards" & absent $^{\mathrm{p}}$ \\
\hline \multicolumn{3}{|l|}{ Shell } & (none found) & footnote ${ }^{q}$ \\
\hline \multirow{4}{*}{\multicolumn{3}{|c|}{ Metal }} & copper bodkin & present \\
\hline & & & veneer on wood and stone & abundant \\
\hline & & & Caucasian fragment (?) & absent \\
\hline & & & galena nodules & abundant $^{\mathrm{r}}$ \\
\hline \multirow[t]{5}{*}{ Miscellaneous: } & \multirow{4}{*}{\multicolumn{2}{|c|}{ pigments }} & red ocre (sic.) & present \\
\hline & & & glauconite (traces) & abundant \\
\hline & & & kaolin & present \\
\hline & & & white carbonate & present $^{\varsigma}$ \\
\hline & other & & & footnote ${ }^{t}$ \\
\hline
\end{tabular}


1. other Spiro burials are urn, cremation, and crib.

2. $\quad$ some Spiro vessels are tempered with quartz grit.

3. add thin brown and thin red-orange (shell) ware to Spiro list.

4. the writer has distinguished 6 bottle types, 10 bowl types, and 6 jar types of vessels in addition to those mentioned above.

5. rarely, red pigment is found in the incisions on Spiro vessels.

6. other Spiro designs: evolving spirals, "waves", concentric circles; bands of cross-hatchuring (rare); negative circles; overhanging lines; triangular punctates.

7. a rare Spiro trait is designs on the inside of bowls,

8. no ceramic pipes at Eufaula; at Spiro, long thin stems with conic bowls.

9. human effigy in kneeling position; animal effigy; double bowl pipes.

10. cross design.

11. polished flint celts; spatulate; long, thin celts.

12. spherical hammerstone (village).

13. locust boatstone of crystal; boatstone; discoidal; plummet; "button"; elliptical metate with concave bowl; elliptical blade.

14. stemmed point with double set of barbs, of extraordinary length.

15. bird on staff; cedar logs in burials; buttons; pulley earspools; eagle head; figurine.

16. antelope jaw.

17. conch shell containers; engraved conch shells with realistic designs; engraved gorgets; seven types of beads including pearls; human figurine; inlay in stone and wood; hoes (lowest level).

18. "breastplates" of copper resembling bird figures (repouses); copper celts (Hyde Museum, N.Y.).

19. yellow pigment; black pigment.

20. cordage; haircloth; feather cloth; textiles; matting (plaid); baskets (coiled); worked leather; quartz crystals; bullet-shaped pyrites; mica fragments.

In comparing the material from Eufaula with that from Spiro certain allowances must be made. While the Eufaula Mound was a small structure containing the remains of a little over 100 individuals, the Spiro Mounds contained the remains of nearly 1000 . Two years were spent in excavating the six mounds and the village site of the Spiro group. Consequently, a much greater volume of material came from this site. We would therefore expect, and rightly so, to find certain artifact types at Spiro that were either unknown to or not manufactured by the Eufaula Mound people. The very size of the site intimates a "village vs. city" situation in which the "city" (Spiro) would have more and perhaps different artifact types. An example of this difference is most strikingly presented in the presence of shell in quantities at Spiro and the complete absence of this perishable material at Eufaula. It is thought that shell, originally present at Eufaula, had decomposed away. The people of the larger site (Spiro), however, were able to amass such quantities of shell (mainly conch) that water leaching at the outer surfaces of the masses produced a local calcium saturation, thus protecting the inner core.

Keeping such data in mind, we may expect by the use of the trait lists to determine the probable relationship of the Eufaula Mound to the Spiro Mounds. 


\section{SUMMARY}

From a study of the Eufaula and Spiro sites trait lists, the following quantitative facts are apparent:

1) Eufaula traits total 78 ; Spiro traits total 177.

2) Seventy-one of Eufaula's 78 traits are present at Spiro.

3) Of the 71 Eufaula traits at Spiro 24 are abundant or "diagnostic". These are also abundant at Eufaula.

4) Six Eufaula traits found at Spiro occur rarely both at Spiro and Eufaula.

5) Only one trait (engraved designs), occurs rarely at Eufaula and abundantly at Spiro.

One of the first facts apparent is that the Spiro traits number well over twice as many as the Eufaula traits. The relative size of the sites would of course be accountable for a portion of the difference. For example, while the six vessels and relatively few sherd fragments found at Eufaula yielded five vessel types (traits), over 300 vessels and vessel fragments at Spiro presented over 38 types. The fact that the Eufaula vessels are all found in abundance at Spiro is a strong point in favor of a close relationship between the two sites. The negative information presented by the lack of some 23 vessel types at Eufaula is purely a quantitative statement, understandable on the basis of the relative size of the sites. It is, therefore, without particular significance in answer- ing the question of the relationship of the two sites. Again, many of the traits found at Spiro are of organic materials which had suffered heavily at Eufaula. Spiro's 15 shell traits may have been present at Eufaula originally. The organic materials such as cordage, textiles, matting, and feather cloth, absent at Eufaula, are represented at Spiro by only a few fragments.

The absence of certain Spiro traits in the Eufaula Mound undoubtedly has some significance. For example, the abundance of engraved designs over incised designs (most common at Eufaula) appears significant. We also find on close scrutiny of the design motifs, that those of Eufaula, though nearly identical in arrangement, are more precisely done than those at Spiro. We may suppose that the absence of the ground stone spatula mace, abundant at Spiro and lacking at Eufaula, may have cultural significance. However, the absence of such Spiro traits as the quartz crystal, boatstone (locust effigy), and the large double bowl, monitor pipe type may have no great meaning for our problem. Such artifacts due to their extreme rarity not only at Spiro but everywhere, must be regarded as local phenomena or trade articles. It is felt that the other differences may be accounted for on the basis of local specialization.

Another set of traits found rarely at Spiro and not at all at Eufaula may have an entirely different significance. Such traits are: shell tempered, thin brown or redorange ware; long stemmed pipes with 
small, conical bowls; designs based on cross-hatched bands, spurred lines, and negative circles in hatched areas; red pigment in incisions; and perhaps urn burials in large, shell tempered jars. These traits seem to contrast sharply with the main run of materials and may represent a second component within the Spiro Mound site. Such material closely resembles that found in villages in the vicinity of the Spiro Mound. At the present time the writer is working on a clearer definition of this second, wellrepresented culture, which might be called the Fort Coffee focus.

The Eufaula traits absent at Spiro (seven in number) may be readily accounted for. Two of the traits, wooden "flint" blades, and bone "wrist guards", are of organic materials that might easily have disappeared in the Spiro site. The two point types, broad campanulated, and triangular, notched with additional horizontal notches in the basal portion, are Eufaula specializations, the basic types of which are found at Spiro. The absence of Caucasian metal at Spiro throws suspicion on the already doubtful metal fragment from Eufaula. Although quartz crystal beads are lacking at Spiro (one from Eufaula) unworked crystals occurred in quantities, and one worked specimen (locust boatstone) is listed. The seventh Eufaula trait absent at Spiro is a bottle type with a hollow, tripod base. The seriousness of this absence is somewhat modified by the presence of solid, tripod bases on other forms (jar). However, it may have some significance.

\section{CONCLUSION}

It has been indicated that fully 71 of Eufaula's 78 traits are present at Spiro. Furthermore, 24 of Eufaula's traits, diagnostic at that site, are also diagnostic at the Spiro site. It has been pointed out that while quantitative and qualitative differences do exist between the two sites, they are due to (1) difference in the relative size of the sites, (2) presence or absence of highly perishable organic materials, (3) local specialization. They are consequently of minimum significance to our problem. Certain traits, however, are present in small numbers at Spiro and absent at Eufaula. These traits may belong to a different component, the focus (Fort Coffee Focus) of which is being defined at the present time. Since the evidence indicates a near-identity relationship between the two components, we feel justified in grouping them in accordance with the principle of the Midwestern Taxonomic System into one focus which may be called the Spiro Focus.

\section{DISCUSSION}

Certain sites bear so striking a similarity to the Spiro Focus as to be included within it. The Brackett site of northeastern

Oklahoma has a house, pottery and burial 
types identical with Spiro. ${ }^{12}$ Gahagan Mound of northwestern Louisiana differs significantly in only a few ceramic traits. ${ }^{13}$ The Mineral Spring sites of southwestern Arkansas have striking similarities, particularly in the ceramic traits. ${ }^{14}$ Again, in northwestern Texas, Sanders' Place contains traits which even, to shell gorgets, might have come from the Spiro Mounds ${ }^{15}$ Finkelstein notes the close relationship between the Norman site of eastern Oklahoma and Spiro, which he unhesitantly places within the same aspect. $^{16}$ The writer suggests that a detailed comparison of trait lists might place the Norman Site in a focus relationship to the other sites listed above.

The aspect affiliation of the Spiro Focus is suggested by a comparison of its traits with those of sites that have been called "Caddoan". Although much abused in the literature, this inappropriate, linguistic term may be said to include Harrington's southwest Arkansas sites, Moore's Red River sites, Ford's Caddo pottery horizon, as well as the sites of northeastern Texas. The similarity of these sites to each other and to the Spiro Focus suggests an aspect grouping. Such as group might be termed the "Caddoan Aspect". Within this large category foci other than Spiro would appear. A "Glendora Focus" might embrace Moore's contact sites on the Ouachita River as well as Ford's and Walker's Louisiana Caddo. The villages surrounding the Spiro Mounds (Moore, Skidgel, Bowman) could be grouped within a "Fort Coffee Focus", and Harrington's Ozan, Washington, and Hot Springs sites could be grouped within an "Ozan Focus". Although entirely speculative at present, a "Caddoan Aspect" consisting of several foci is strongly suggested by the "Caddoan" material. The plausibility of such a setup has been stressed in the unpublished worked of Deuel ${ }^{17}$ and Bennett ${ }^{18}$.

The broad Mississippi pattern traits as outlined by Cole and Deuel ${ }^{19}$ easily embrace the Spiro Focus. We note that the Upper Mississippi forms are similar, but entirely too simplified to account for the richly variegated culture of the Spiro Focus. The list of determinants for the Middle Mississippi more closely resemble those of our Focus ${ }^{20}$. With the exception of pottery trowels, all traits listed are present or abundant at Spiro. However, while mounds of the Middle Mississippi are used primarily as substructures, Spiro mounds are mainly burial receptacles. Again, the Middle Mississippi pottery seems to be less "ornate" than that of the Caddoan area. Such differences might contribute to the controversy as to whether or not a "lower" phase of the Mississippi would, of necessity, reopen the problem of phase affiliation.

It must always be remembered that a classification of cultures is merely a tool with which to reconstruct the past. It is, nevertheless, a most necessary tool. The material facts of aboriginal groups must be established before temporal and spacial (sic.) questions concerning them can be answered. For this reason, the Midwestern Taxonomic System, embracing as it does total material cultures, is an excellent device for working out uncharted histories. The continued use of this system will solve many problems of cultural 
relationships in the "Caddoan" area in particular, and in the New World, in general. To this vast task this paper may represent a small contribution.

\section{END NOTES}

${ }^{1}$ Fred Carder, David Baerreis, Lynn Howard, and Carl Ball also supervised the work on the "Great Temple" mound.

${ }^{2}$ Orr, K.G., "Field Report on Excavation of Indian Villages in the Vicinity of the Spiro Mounds", The Oklahoma Prehistorian, Vol. II, no. 2, July, 1939.

${ }^{3}$ McKern, C.W., "The Midwestern Taxonomic Method as an Aid to Archaeological Culture Study", American Antiquity, Vol. IV, no. 4, pp. 3301-313, April 1939.

${ }^{4}$ Cole, Fay-Cooper, and Deuel, Thorne, Rediscovering Illinois, p. 207, University of Chicago Press, 1937.

${ }^{5}$ McKern, op. cit., p. 310.

${ }^{6}$ Cole and Deuel, op. cit., p. 278.

${ }^{7}$ Cole and Deuel, op. cit., p. 207.

${ }^{8}$ Swanton, J.R., "Archaeological Culture Areas" in Conference on Southern Prehistory, National Research Council, Dec. 1932, Fig. 7.

${ }^{9}$ This excavation was undertaken by the Okmulgee Museum in the summer of 1939. Mr. Otto Spring directed the dig.

${ }^{10}$ Although both the village and the mounds of the Spiro Site were excavated, only the material from the mounds will appear in the trait list.

11 "Trait" is used as defined by Dr. Fay-Cooper Cole: any feature, artifact, or artifact characteristic (in short, anything found in a site) which may be of use in cultural diagnosis. A "diagnostic trait" is one which occurs a number of times, indicating its importance in a complex of traits. F.C. Cole, lecture in North American Archaeology, University of Chicago, Nov. 26, 1940.

${ }^{12}$ Howard, Lynn, "The Brackett Site", The Oklahoma Prehistorian, Vol. III, no, 1, p. 2, Jan, 1940.

${ }^{13}$ Webb and Dodd, "The Gahagan Mound", TAPS, Vol. II, pp. 92-125, 1939; and Moore, Clarence B., "Site on the Red River", JANS, Vol. IV, 1912.

${ }^{14}$ Harrington, M.R., "Caddo Site in Arkansas", MAI, p. 23, 1920 
${ }^{15}$ Pearce, "Archaeology of East Texas", American Antiquity, Vol. 24, pp. 670-687.

${ }^{16}$ Finkelstein, The Norman Site, The Oklahoma Prehistorian 3(3):15, Dec. 1940.

17 Deuel, Thorne, "Pictorial Survey of the Mississippi Valley", Unpublished MS, Dept. of Anthropology, University of Chicago.

${ }^{18}$ Bennett, John, "The Caddoan Problem", Unpublished MS, Dept. of Anthropology, University of Chicago. The writer wishes here to acknowledge the aid so generously given by Mr. Bennett during the preparation of the Eufaula Mound paper.

${ }^{19}$ Cole and Deuel, op. cit., p. 36.

${ }^{20}$ Ibid, Table 2.

\section{ADDITIONAL REFERENCES FOR THE EUFAULA SITE (34MI45)}

\section{Bell, Robert E.}

1984 Arkansas Valley Caddoan: The Harlan Phase. In: Prehistory of Oklahoma, Robert E. Bell (editor). Academic Press, Orlando.

Orr, Kenneth G.

1942 The Eufaula Mound, Oklahoma: Contributions to the Spiro Focus. Unpublished M. A. thesis, Department of Anthropology, The University of Chicago.

1952 Survey of Caddoan Area Archeology. In: Archeology of the Eastern United States, James B. Griffin (editor). The University of Chicago Press, Chicago.

Wyckoff, Don Gale

1980 Caddoan Adaptive Strategies in the Arkansas Basin, Eastern Oklahoma. Unpublished Ph.D. dissertation, Department of Anthropology, Washington State University, Pullman. 